OPEN ACCESS

Edited by: Yousif El Safi Himeidan, Africa Technical Research Centre, Tanzania

Reviewed by: Durg Vijai Singh, Institute of Life Sciences, India Eliningaya Kweka, Tropical Pesticides Research institute, Tanzania

*Correspondence: Guiyun Yan guiyuny@uci.edu

Specialty section: This article was submitted to Environmental Health, a section of the journal Frontiers in Public Health

Received: 29 February 2016 Accepted: 12 July 2016 Published: 15 August 2016

Citation:

Zhou G, Lee M-C, Githeko AK,

Atieli HE and Yan G (2016)

Insecticide-Treated Net Campaign and Malaria Transmission in Western Kenya: 2003-2015.

Front. Public Health 4:153. doi: 10.3389/fpubh.2016.00153

\section{Insecticide-Treated Net Campaign and Malaria Transmission in Western Kenya: 2003-2015}

\author{
Guofa Zhou', Ming-Chieh Lee', Andrew K. Githeko' ${ }^{2}$, Harrysone E. Atieli ${ }^{2}$ and Guiyun Yan ${ }^{1 *}$ \\ ${ }^{1}$ Program in Public Health, University of California Irvine, Irvine, CA, USA, ${ }^{2}$ Centre for Global Health Research, Kenya \\ Medical Research Institute, Kisumu, Kenya
}

Insecticide-treated nets (ITNs) are among the three major intervention measures that have reduced malaria transmission in the past decade. However, increased insecticide resistance in vectors, together with outdoor transmission, has limited the efficacy of the ITN scaling-up efforts. Observations on longitudinal changes in ITN coverage and its impact on malaria transmission allow policy makers to make informed adjustments to control strategies. We analyzed field surveys on ITN ownership, malaria parasite prevalence, and malaria vector population dynamics in seven sentinel sites in western Kenya from 2003 to 2015. We found that ITN ownership has increased from an average of $18 \%$ in 2003 to $85 \%$ in 2015 . Malaria parasite prevalence in school children decreased by about 70\% from 2003 to 2008 (the first mass distribution of free ITNs was in 2006) but has resurged by $>50 \%$ since then. At the community level, use of ITNs reduced infections by $23 \%$ in 2008 and $43 \%$ in 2010, although the reduction was down to $25 \%$ in 2011. The indoor-resting density of the predominant vector, Anopheles gambiae, has been suppressed since 2007; however, Anopheles funestus populations have resurged and have increased 20-fold in some places since 2007. In conclusion, there is limited room for further increase in ITN coverage in western Kenya. The rebounding in malaria transmission highlights the urgent need of new or improved malaria control interventions so as to further reduce malaria transmission.

Keywords: insecticide-treated net, ownership, malaria parasite prevalence, vector density, cross-sectional survey, resurgence

\section{INTRODUCTION}

The scale-up of interventions, including insecticide-treated nets (ITNs), indoor residual sprays (IRS), and artemisinin-based combination therapy (ACT), has led to a significant reduction in malaria morbidity and mortality in the past decade (1). Long-lasting insecticidal nets (LLINs) have been a cornerstone of malaria control in the past several years, and millions are used each day across the globe (2). There is abundant literature about the success of the scale-up in suppressing malaria transmission, but there is also mounting evidence showing the limitations of these interventions (3-15). Factors limiting the effectiveness of ITNs include vector insecticide resistance due to selection pressure over time (16-19), outdoor biting and resting to avoid physical contact with ITNs (20-25), species shifting from mainly indoor-biting and resting species to more outdoor-resting species $(11,26)$, vectors biting animals $(27)$, insecticide decay $(28,29)$, and varying durability of LLINs under different conditions of use (30). 
Kenya is one of the south Saharan African countries where malaria is most prevalent (1). Western Kenya currently has the highest malaria transmission intensity in the country $(1,31)$. Similar to the rest of the world, the major ITN, IRS, and ACT campaign in Kenya began in 2006 (11). ITN coverage was low in Kenya before 2006, although retail and subsidized ITN campaigns were initiated in early 2000 (11). In 2006, the Ministry of Health began mass distribution of free ITNs to children under 5 years and pregnant women $(11,30)$. In 2011, the policy changed to cover the entire at-risk population regardless of age and gender (30). In 2014, the third round of mass LLIN distribution was launched to boost ITN coverage and replace old ITNs (30). These mass campaigns significantly increased overall ITN coverage $(14,30)$. However, evidence shows a mixed picture of the success of the current scaled-up antimalarial campaign. While some earlier studies reported a continuous decline in malaria transmission in selected sites (32-35), more recent studies show that malaria transmission has remained unchanged or has even resurged in western Kenya $(11,14)$. Possible risk factors limiting the effectiveness of ITNs have been explored, including vector insecticide resistance, outdoor transmission, vector species shifting, vectors biting animals, insecticide decay, and the varying integrity of LLINs under different conditions of use $(14,18,25,27,28)$. However, no study has looked into the effectiveness of ITNs over time to compare the impact of ITNs on malaria transmission at different periods - e.g., before or immediately after the first mass ITN campaign in 2006 compared with now, about 10 years later. This knowledge would be valuable to malaria control programs as they plan for procurement and replacement.

The aim of this study is to explore the changes in ITN coverage since 2003, 3 years before the scaled-up antimalarial campaign began, and compares the effectiveness of ITNs on vector indoorresting density and parasite prevalence over time (i.e., before, immediately after, and about 10 years after the first mass ITN campaign). We aim to determine whether adherence to, and public health benefits of, insecticide-treated bednets can be sustained over time, i.e., maintains malaria vector population and parasite prevalence at low levels.

\section{MATERIALS AND METHODS}

\section{Study Area}

This study was conducted in seven sites in four counties in western Kenya: Kakamega County, Vihiga County, Kisumu County, and Kisii County (Figure 1). The study area includes both highand low-transmission sites and both highlands and lowlands (Table S1 in Supplementary Material) $(18,25,28,30)$. The details of climate, geography, and malaria transmission in the area have been described elsewhere $(11,25,30)$. Briefly, all study sites are located in hilly areas, with altitudes ranging from $1180 \mathrm{~m}$ above sea level (a.s.l.) in Kombewa to $1770 \mathrm{~m}$ a.s.l. in Marani (Figure 1). Each site has distinct topology, but all seven sites are characterized by valleys surrounded by hills of different slopes. Climate in the study area consists mainly of two seasons of rainfall: a long season between March and May (the peak malaria transmission season) and a short one between October and November.

\section{ITN Ownership and Usage Survey}

Insecticide-treated net ownership was surveyed in three villages: Iguhu, Kombewa, and Marani. The detailed field surveys have been described in previous studies (30). Briefly, ITN ownership and usage surveys were conducted along with monthly entomological surveillance. This arrangement saved time and money and avoided logistical issues, such as transportation and manpower; this method has been validated by cross-sectional surveys (30). Houses at each site were randomly selected for participation. Owners of the selected houses were requested to sign a freely administered informed consent form covering participation in the study, questionnaire surveys of ITN ownership and monitoring of ITN conditions, and demographic information. ITN ownership was surveyed in 2003, 2006, and every year from 2008 to 2015.

\section{Malaria Vector Surveys}

Malaria vectors were sampled in Iguhu, Kombewa, and Marani in 2003, 2008, 2011, and 2015 (Tables S1 and S2 in Supplementary Material). Pyrethrum spray collections were conducted monthly in 30 randomly selected sentinel houses in each village for 12 months each year. The houses were chosen to cover at least three elementary school areas. The selection of houses to be sampled was re-randomized each month, but the sampled houses were all located in the same general area from 2003 to 2015. The presence or absence of ITNs in each house was also confirmed and recorded during mosquito sampling. Mosquitoes collected were morphologically identified as Anopheles gambiae s.l. or Anopheles funestus.

\section{Cross-Sectional Asymptomatic Parasite Screening}

Asymptomatic malaria parasite infection surveys were conducted in different communities in 2006, 2010, and 2011 (Tables S1 and S2 in Supplementary Material). Surveys were done once a year during the high-transmission months of May and June. The surveys included all ages. To maximize the representativeness of the samples, the sampling area was stratified to cover three elementary schools in each study site, and participants were selected randomly from each school catchment area. Upon signing the informed consent (assent for minors under age 18) forms, participants completed a short questionnaire survey that included demographic and ITN ownership/usage information. Blood samples were collected by the standard finger-prick method (11), and thin and thick blood smears were prepared for laboratory examination. Parasite species and gametocytes were identified microscopically. Malaria parasite counts were read against 200 white blood cells, and density was expressed as parasites per milliliter assuming a count of 8,000 white blood cells per microliter. All slides were examined by two experienced laboratory technicians at Kenya Medical Research Institute (KEMRI) to identify the parasite species. For quality control purposes, a third technician randomly selected $5 \%$ of the slides for re-examination.

\section{Parasite Screening in School Children}

Parasitological surveys were conducted with randomly selected school children aged 6-13 years in Iguhu, Kombewa, 


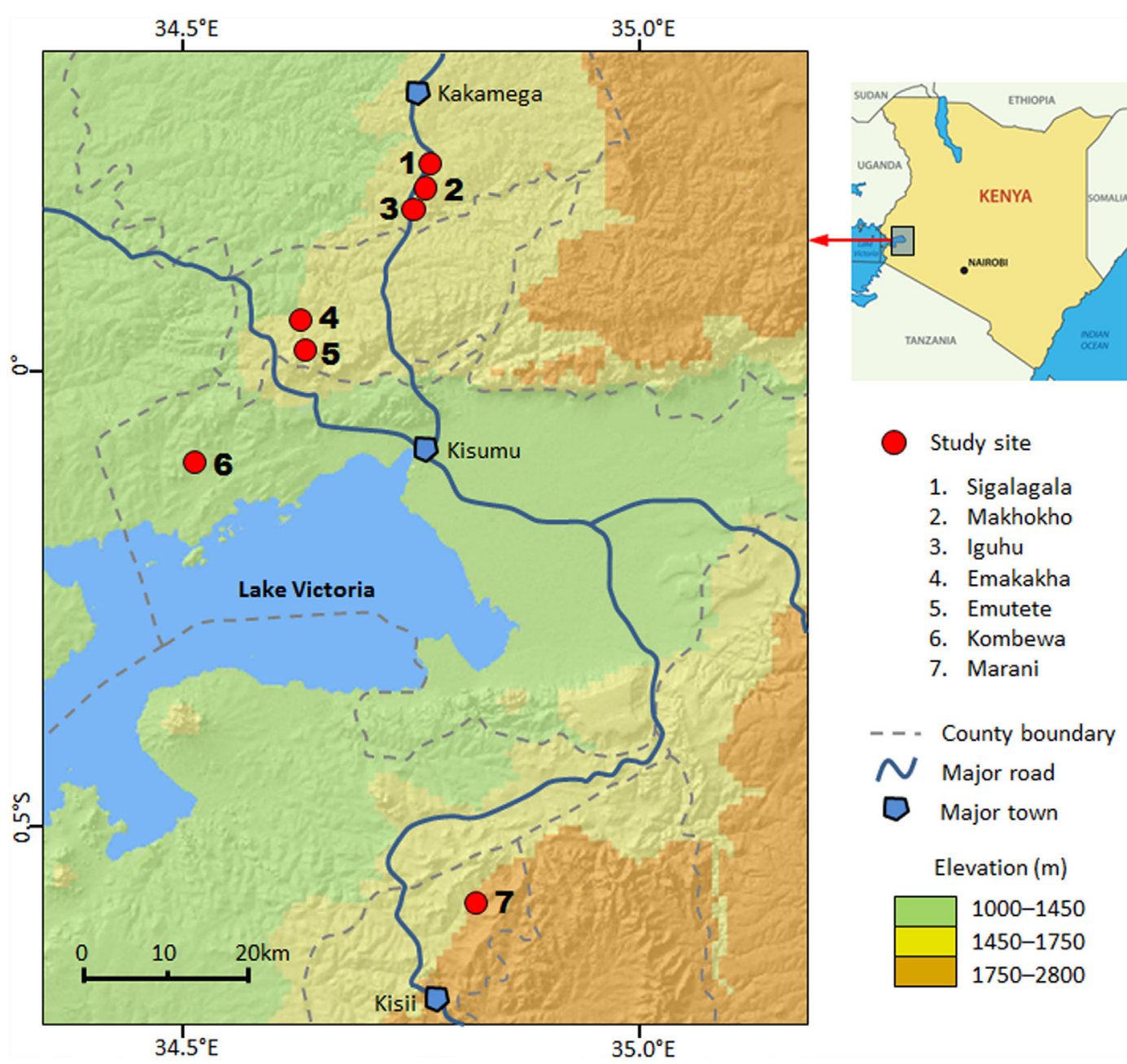

FIGURE 1 | Map of sampling sites in western Kenya.

and Marani (Tables S1 and S2 in Supplementary Material) (11). Data used in this study included February, April, and June surveys from 2003, 2008, 2011, and 2015. During each sampling occasion at each site, at least 100 volunteer school children from 5 to 6 primary schools were sampled to determine parasite prevalence. The catchment area at all sites remained unchanged over time. During high-transmission season (June of each year), we increased the sample size to 300 volunteers to increase the statistical power. Blood sample collection, slide preparation, parasite identification, and parasitemia counts were conducted as described in the previous section. This survey was purely for parasite screening; no questionnaire was administered.

\section{Data Analysis}

Household ITN ownership was calculated as the percentage of households with at least one ITN during the survey. Parasite prevalence was calculated as the percentage of positive cases over total slides examined, based on pooling all surveys in each year at each site. Indoor-resting malaria vector density was calculated as females per house per night, pooled by month at each site. Percentage reduction in indoor-resting vector density between households with ITN and without ITN was calculated as

(mean density in households with ITNs) $\frac{\text { (mean density in households without ITNs) }}{\text { (mean density in households with ITNs) }} \times 100$.

Differences in vector densities between different years and between ITN owners and non-owners were compared using a $t$-test or ANOVA. Differences in parasite prevalence between different years were compared using a $\chi^{2}$ test.

\section{Scientific and Ethical Clearance}

Scientific and ethical clearance was given by the institutional review boards (IRBs) of KEMRI, Kenya, and the University of California at Irvine, USA. Volunteers were enrolled from primary schools in the study sites through school administrators with the permission of the division office of the Ministry of Health. Written assent for children ( $<18$ years of age) was obtained by 
the participants and their parents or guardians. Written consent and assent for households was obtained from the head of the household. Inclusion criteria included providing informed consent and having no reported chronic or acute illness except malaria. Exclusion criteria included unwillingness to participate in the study. According to the standard malaria treatment guidelines of the Ministry of Health of Kenya, asymptomatic infections were not treated with antimalarials. Symptomatic volunteers were referred to the local government hospital or clinic for diagnosis and treatment free of charge.

\section{RESULTS}

Household ITN ownership increased from an average of $18.3 \%$ in 2003 to $85.3 \%$ in 2015 (Figure 2). The sharpest increase in ITN ownership occurred from 2006 to 2011 , and the positive trend began to slow in 2012 (Figure 2). Although there was a mass ITN distribution in the study area in 2014, ITN ownership only increased by about $3 \%$ from 2013 to 2015 . In fact, ITN ownership has decreased by about 4\% in Iguhu from 2012 to 2015 (Figure 2). Presumably the 2014 ITN campaign mainly replaced old ITNs as opposed to introducing ITNs into homes that had not had them before.

Parasite prevalence in school children decreased sharply at all sites from 2003 to 2008 ( $\chi^{2}$ tests, $P<0.01$ at all sites) (Figure 3). The average reduction in parasite prevalence in this period was 70.5\%. Parasite prevalence dropped continuously from 2008 to 2011 in two sites, whereas it increased twofold in one site (Figure 3). Compared to 2008, parasite prevalence in 2015 had increased by an average of $57.5 \%$.

Compare to non-users, use of ITNs reduced communitywide parasite prevalence by $23.6 \%$ in 2006 . The reduction in parasite prevalence by the use of ITNs compare to non-users increased to $43.3 \%$ in 2010 but decreased to $25.6 \%$ in 2011 (Table 1).

Total vector density was $82.9 \%$ lower on average in 2008 compared to 2003 (ranging from 61.0 to $100 \%$ lower), while

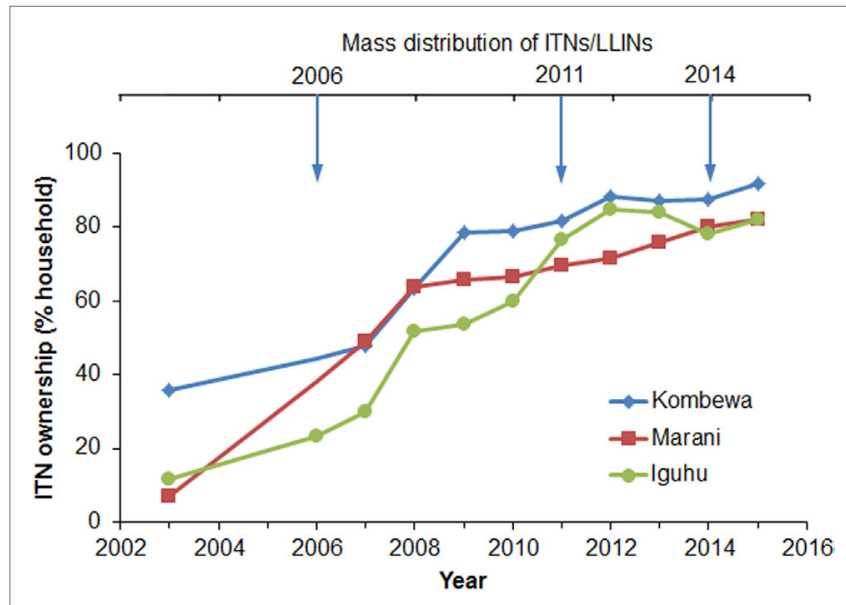

FIGURE 2 | Dynamics of ITN ownerships from 2003 to 2015 at three study sites in western Kenya. blood-fed vector density decreased by $93.4 \%$ (ranging from 84.2 to $100 \%)$. Vector density was significantly lower in 2008 compared to 2003 regardless of species and study site (Figure 4). The pyrethrum spray collection method did not find any indoorresting malaria vectors in Marani in 2008. Since 2008, the density of indoor-resting A. gambiae s.l. has remained unchanged in Kombewa and Iguhu but has resurged in Marani, although it is still significantly lower than in 2003 (Figure 4). By contrast, the density of $A$. funestus has rebounded significantly at all sites since 2011 (Figure 5), and in Marani A. funestus density was 20-fold higher in 2015 (1.02 females/house/night) compared to 2003 (0.05 females/house/night) (unequal variance $t$-test, $t=6.10$, d.f. $=7, P<0.001)$.

Use of ITNs reduced indoor-resting A. gambiae s.l. density by an average of $36.8 \%$ in 2008 compare to non-users, but the reduction decreased to $9.9 \%$ in 2015 (Table 2). Use of ITNs did not reduce indoor-resting $A$. funestus density regardless of ITN coverages, i.e., in both 2008 when ITN coverage was low and 2015 when ITN coverage was high. Reduction in blood-fed density due to ITNs was insignificant regardless of vector species and ITN coverages (Table 2 ).

\section{DISCUSSION}

Insecticide-treated nets have proven to be one of the most effective tools for malaria control (1, 2, 36-39). In the 1990s, ITNs sustainably reduced malaria transmission, especially malaria-specific mortality, when they were first introduced into

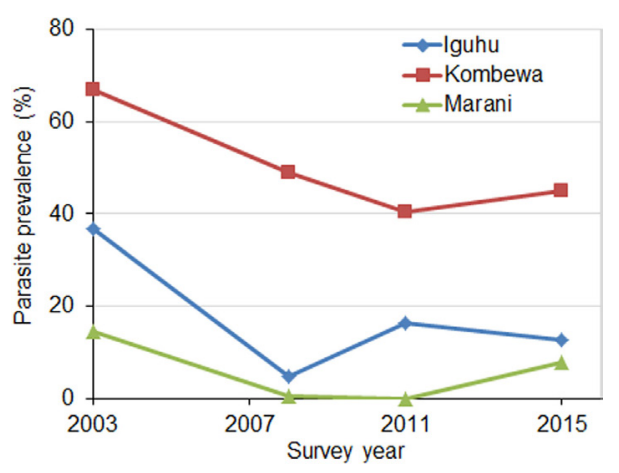

FIGURE 3 | Parasite in school children from 2003 to 2015 at three study sites in western Kenya.

TABLE 1 | ITN coverage and differences in parasite prevalence between ITN users and non-users.

\begin{tabular}{llccc}
\hline Indicator & & \multicolumn{3}{c}{ Survey year } \\
\cline { 3 - 5 } & & $\mathbf{2 0 0 6}$ & $\mathbf{2 0 1 0}$ & $\mathbf{2 0 1 1}$ \\
\hline ITN usage & & $23.30 \pm 1.08$ & $43.77 \pm 8.44$ & $85.59 \pm 14.01$ \\
Parasite & Overall (\%) & $15.12 \pm 9.63$ & $12.88 \pm 6.18$ & $11.73 \pm 9.95$ \\
prevalence & & & & \\
& With ITN (\%) & $11.51 \pm 5.65$ & $9.07 \pm 4.83$ & $11.22 \pm 10.56$ \\
& No ITN (\%) & $16.17 \pm 10.74$ & $16.28 \pm 7.47$ & $13.66 \pm 4.59$ \\
& Reduction (\%) & $23.60 \pm 13.44$ & $43.32 \pm 13.22$ & $25.63 \pm 47.71$
\end{tabular}



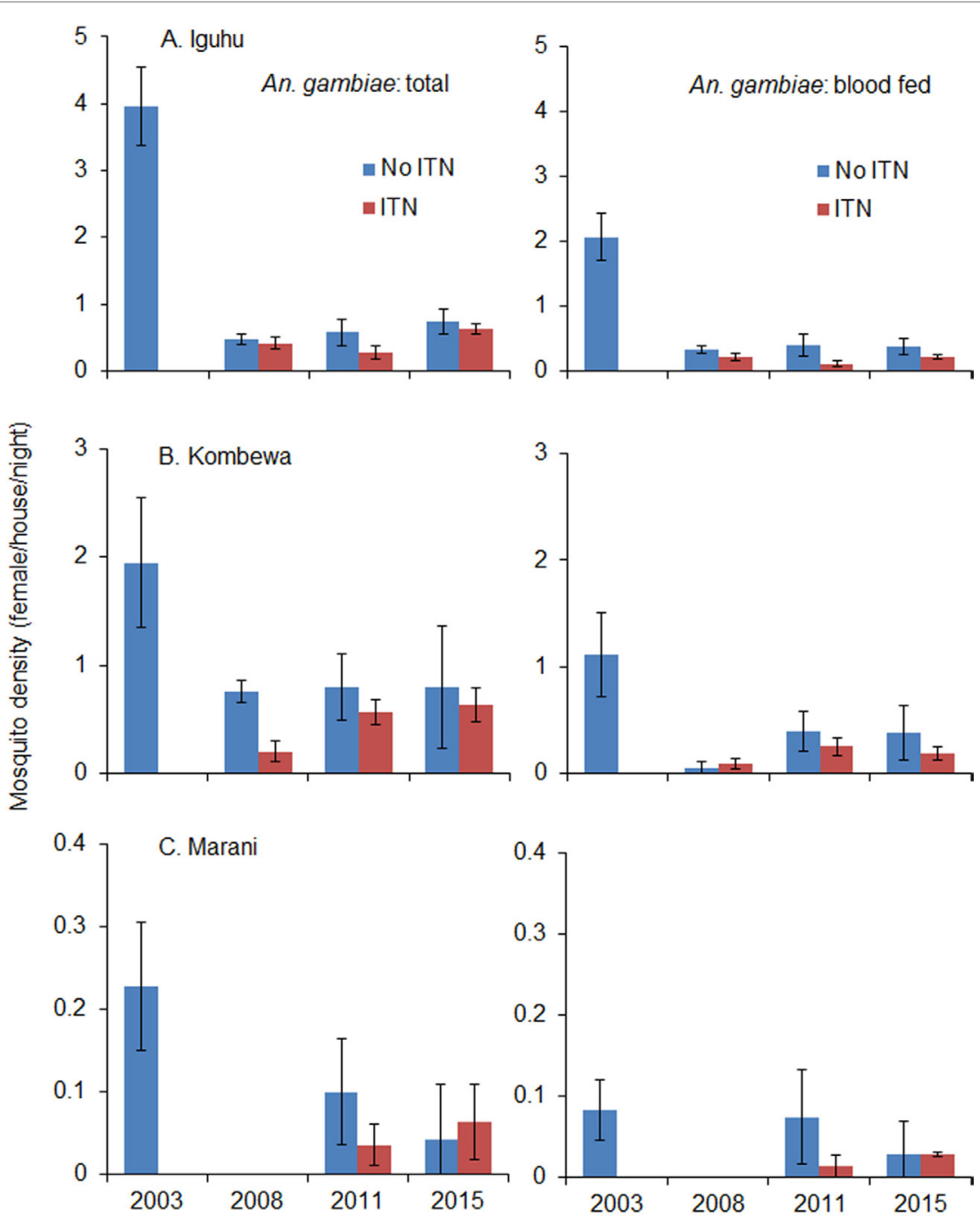

Survey year

FIGURE 4 | Impact of ITN usage on indoor-resting malaria vector densities from 2003 to 2015 at three study sites in western Kenya. (A) Iguhu, (B) Kombewa, (C) Marani.

communities $(32,36)$. Over the past decade, ITNs, together with other interventions, have saved millions of lives and effectively reduced malaria transmission all over the world $(1,2)$. However, recent studies show a resurgence in malaria transmission despite high ITN coverage $(7,14)$. While there has been limited epidemiologic data demonstrating that pyrethroid resistance reduces the effectiveness of ITNs, several studies conducted in pyrethroid-resistant areas have demonstrated the continued ability of ITNs to protect against malaria transmission when properly deployed (19, 40-42). Conclusions from different studies can be contradictory; some studies conclude that ITNs did not provide significant personal protection (43), while studies from the same area suggest that ITNs significantly reduced the incidence of malaria infection (44). This study shows that ITNs still have a significant community-wide effect on reducing the overall parasite prevalence, despite the resurgence of indoorresting vectors.
Although recent studies and meta-analysis of entomologic outcomes have shown that ITNs continued to reduce blood feeding and increase mosquito mortality even in areas with the highest levels of resistance (45), this study did not find significant reduction in indoor-resting vector densities in households with ITNs compared to households without ITNs. The sharp decrease in indoor-resting vector density in 2008 is likely due to a community-wide effect when insecticide resistance was low. The stability of indoor-resting A. gambiae s.l. may be due to three factors: ITNs remaining effective against A. gambiae s.s., vector species shifting toward Anopheles arabiensis, and vectors feeding and resting outdoors $(11,18$, 25-27). A. gambiae s.l. has definitely developed resistance to pyrethroid insecticides in western Kenya, but insecticides still kill over $70 \%$ of mosquitoes when tested against the WHO tube bioassay (18). On the other hand, A. arabiensis has been increasing in the study area relative to $A$. gambiae s.s. $(11,25)$. 

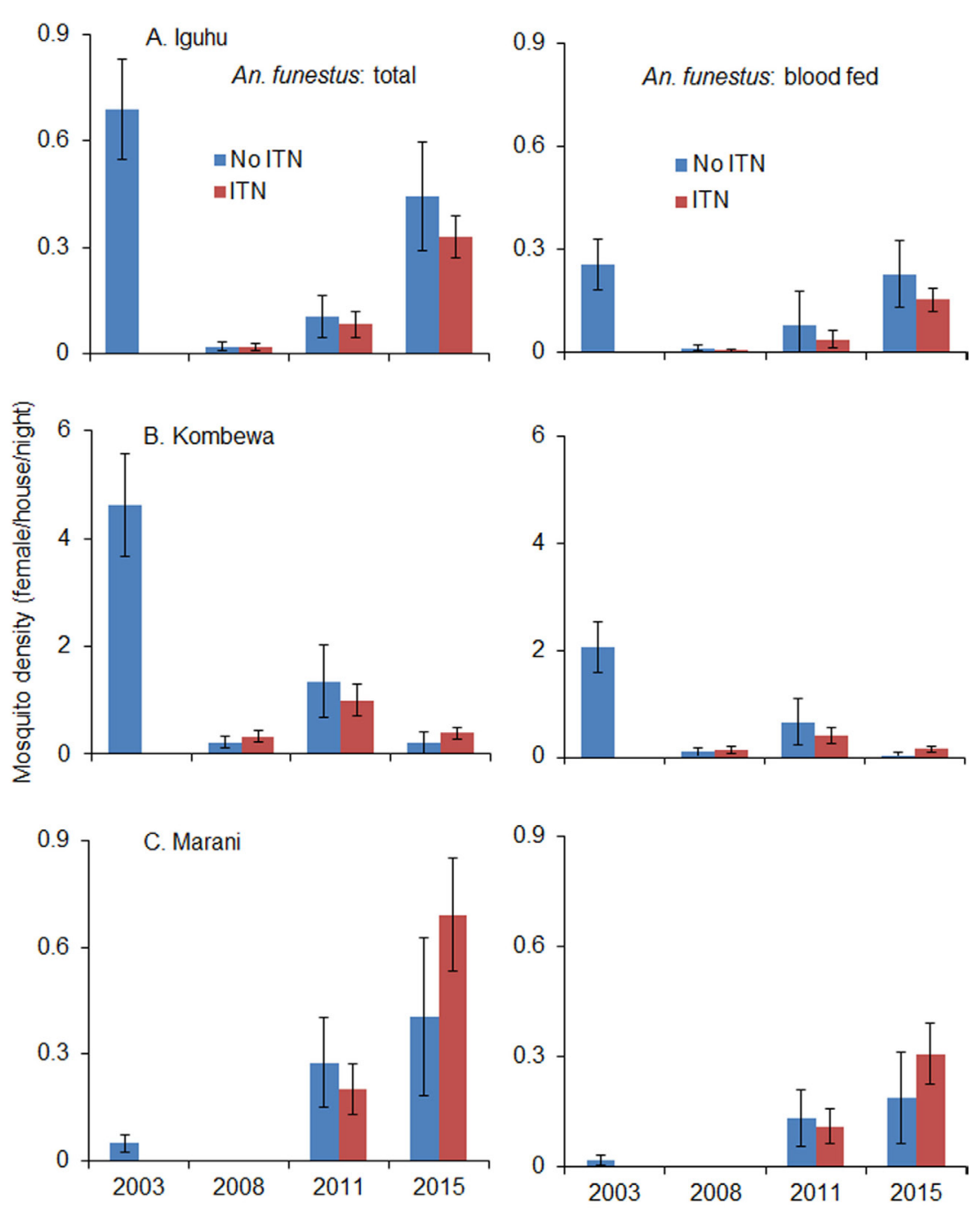

Survey year

FIGURE 5 | Impact of ITNs on A. funestus densities over time at (A) Iguhu, (B) Kombewa and (C) Marani.

TABLE 2 | Percentage reduction in indoor-resting vector density between households with ITN and without ITN.

\begin{tabular}{lrcrc}
\hline \multirow{2}{*}{ Year } & \multicolumn{2}{c}{ A. gambiae } & \multicolumn{2}{c}{ A. funestus } \\
\cline { 2 - 5 } & Total & Blood-fed & Total & Blood-fed \\
\hline 2008 & 36.8 & -48.9 & -25.3 & -22.3 \\
2011 & 13.6 & 16.7 & 11.6 & 16.9 \\
2015 & 9.9 & 24.8 & -22.7 & -46.9 \\
\hline
\end{tabular}

For example, in Kombewa, A. arabiensis accounted for $<5 \%$ of A. gambiae s.l. in 2003 but had increased to $74 \%$ in 2014 $(11,25)$. A. arabiensis rests outdoors more often and feeds on both humans and animals (27). Outdoor transmission has also been observed in the study area $(14,25,27)$. The increase in indoor-resting $A$. funestus density is likely due to insecticide resistance, insecticide decay, and a lack of physical durability in LLINs $(28,30,46-48)$.

\section{CONCLUSION}

Insecticide-treated nets still have a significant community-wide effect on reducing overall parasite prevalence. The use of ITNs is still effective against $A$. gambiae s.s. but it faces the challenges of species shift and increasing insecticide resistance and outdoor transmission. The resurgence of indoor-resting A. funestus indicates that $A$. funestus may be more resistant to ITN use and potentially become the most important malaria vector in western Kenya. The shift in pattern of mosquito species from A. gambiae to A. funestus, which can survive on both human and animal blood, therefore, may pose a problem in future, this situation must be closely monitored. There is also a need to continuously evaluate the use of ITN and insecticide resistance. While the causes may be complex, all evidence points toward the reduction in malaria transmission reaching a plateau in the study area. This calls for the development and adoption of viable alternative 
methods of malaria vector control that can reduce the reliance on pyrethroids.

\section{AUTHOR CONTRIBUTIONS}

Designed the study: GZ and GY; performed statistical analysis and data preparation: GZ; contributed to data collection: GZ, M-CL, HA, and AG; wrote the paper: GZ and GY; and contributed to the final version and interpretation of results: GZ, AG, and GY.

\section{ACKNOWLEDGMENTS}

The authors wish to thank the field team for their years of hard work and for technical assistance in the field and laboratory.

\section{REFERENCES}

1. World Health Organization. World Malaria Report 2012. Geneva: WHO (2012).

2. World Health Organization. World Malaria Report 2015. Geneva: WHO (2015).

3. Karema C, Aregawi MW, Rukundo A, Kabayiza A, Mulindahabi M, Fall IS, et al. Trends in malaria cases, hospital admissions and deaths following scale-up of anti-malarial interventions, 2000-2010, Rwanda. Malar J (2012) 11:236. doi:10.1186/1475-2875-11-236

4. Noor AM, Kinyoki DK, Mundia CW, Kabaria CW, Mutua JW, Alegana VA, et al. The changing risk of Plasmodium falciparum malaria infection in Africa 2000-10: a spatial and temporal analysis of transmission intensity. Lancet (2014) 383:1739-47. doi:10.1016/S0140-6736(13)62566-0

5. Trape J-F, Tall A, Sokhna C, Ly AB, Diagne N, Ndiath O, et al. The rise and fall of malaria in a west African rural community, Dielmo, Senegal, from 1990 to 2012: a 22 year longitudinal study. Lancet Infect Dis (2014) 14:476-88. doi:10.1016/S1473-3099(14)70712-1

6. Coulibaly D, Travassos MA, Kone AK, Tolo Y, Laurens MB, Traore K, et al. Stable malaria incidence despite scaling up control strategies in a malaria vaccine-testing site in Mali. Malar J (2014) 13:374. doi:10.1186/1475-287513-374

7. Jagannathan P, Muhindo MK, Kakuru A, Arinaitwe E, Greenhouse B, Tappero J, et al. Increasing incidence of malaria in children despite insecticide-treated bed nets and prompt anti-malarial therapy in Tororo, Uganda. Malar J (2012) 11:435. doi:10.1186/1475-2875-11-435

8. Trape J-F, Tall A, Diagne N, Ndiath O, Ly AB, Faye J, et al. Malaria morbidity and pyrethroid resistance after the introduction of insecticide-treated bednets and artemisinin-based combination therapies: a longitudinal study. Lancet Infect Dis (2011) 11:925-32. doi:10.1016/S1473-3099(11)70194-3

9. Murhandarwati EE, Fuad A, Nugraheni MD, Sulistyawati, Wijayanti MA, Widartono BS, et al. Early malaria resurgence in pre-elimination areas in Kokap Subdistrict, Kulon Progo, Indonesia. Malar J (2014) 13:130. doi:10.1186/1475-2875-13-130

10. Okiro EA, Bitira D, Mbabazi G, Mpimbaza A, Alegana VA, Talisuna AO, et al. Increasing malaria hospital admissions in Uganda between 1999 and 2009. BMC Med (2011) 9:37. doi:10.1186/1741-7015-9-37

11. Zhou G, Afrane YA, Vardo-Zalik AM, Atieli H, Zhong D, Wamae P, et al. Changing patterns of malaria epidemiology between 2002 and 2010 in Western Kenya: the fall and rise of malaria. PLoS One (2011) 6:e20318. doi:10.1371/journal.pone.0020318

12. Kamya MR, Arinaitwe E, Wanzira H, Katureebe A, Barusya C, Kigozi SP, et al. Malaria transmission, infection, and disease at three sites with varied transmission intensity in Uganda: implications for malaria control. Am J Trop Med Hyg (2015) 5:903-12. doi:10.4269/ajtmh.14-0312

13. Kibret $\mathrm{S}$, Wilson GG, Tekie H, Petros B. Increased malaria transmission around irrigation schemes in Ethiopia and the potential of canal water management for malaria vector control. Malar J (2014) 13:360. doi:10.1186/1475-2875$13-360$
We are grateful to the communities for their support and willingness to participate in this research.

\section{FUNDING}

This project was funded by the National Institutes of Health (D43 TW01505 and R01 A1050243). No funding bodies had any role in study design, data collection and analysis, decision to publish, or preparation of the manuscript.

\section{SUPPLEMENTARY MATERIAL}

The Supplementary Material for this article can be found online at http://journal.frontiersin.org/article/10.3389/fpubh.2016.00153

14. Bayoh MN, Walker ED, Kosgei J, Ombok M, Olang GB, Githeko AK, et al. Persistently high estimates of late night, indoor exposure to malaria vectors despite high coverage of insecticide treated nets. Parasit Vectors (2014) 7:380. doi:10.1186/1756-3305-7-380

15. Ngufor C, Chouaïbou M, Tchicaya E, Loukou B, Kesse N, N'Guessan R, et al. Combining organophosphate-treated wall linings and long-lasting insecticidal nets fails to provide additional control over long-lasting insecticidal nets alone against multiple insecticide-resistant Anopheles gambiae in Côte d'Ivoire: an experimental hut trial. Malar J (2014) 13:396. doi:10.1186/1475-2875-13-396

16. Coetzee M, Koekemoer LL. Molecular systematics and insecticide resistance in the major African malaria vector Anopheles funestus. Annu Rev Entomol (2013) 58:393-412. doi:10.1146/annurev-ento-120811-153628

17. Silva AP, Santos JM, Martins AJ. Mutations in the voltage-gated sodium channel gene of anophelines and their association with resistance to pyrethroids - a review. Parasit Vectors (2014) 7:450. doi:10.1186/1756-3305-7-450

18. Wanjala CL, Mbugi JP, Ototo E, Gesuge M, Afrane YA, Atieli HE, et al. Pyrethroid and DDT resistance and organophosphate susceptibility among Anopheles spp. mosquitoes, Western Kenya. Emerg Infect Dis (2015) 21:217881. doi:10.3201/eid2112.150814

19. Strode C, Donegan S, Garner P, Enayati AA, Hemingway J. The impact of pyrethroid resistance on the efficacy of insecticide-treated bed nets against African anopheline mosquitoes: systematic review and meta-analysis. PLoS Med (2014) 11:e1001619. doi:10.1371/journal.pmed.1001619

20. Moiroux N, Gomez MB, Pennetier C, Elanga E, Djenontin A, Chandre F, et al. Changes in Anopheles funestus biting behavior following universal coverage of long-lasting insecticidal nets in Benin. J Infect Dis (2012) 206:1622-9. doi:10.1093/infdis/jis565

21. Reddy MR, Overgaard HJ, Abaga S, Reddy VP, Caccone A, Kiszewski AE, et al. Outdoor host seeking behaviour of Anopheles gambiae mosquitoes following initiation of malaria vector control on Bioko Island, Equatorial Guinea. Malar $J$ (2011) 10:184. doi:10.1186/1475-2875-10-184

22. Russell TL, Govella NJ, Azizi S, Drakeley CJ, Kachur SP, Killeen GF. Increased proportions of outdoor feeding among residual malaria vector populations following increased use of insecticide treated nets in rural Tanzania. Malar J (2011) 10:80. doi:10.1186/1475-2875-10-80

23. Stevenson J, St Laurent B, Lobo NF, Cooke MK, Kahindi SC, Oriango RM, et al. Novel vectors of malaria parasites in the western highlands of Kenya. Emerg Infect Dis (2012) 18:1547-9. doi:10.3201/eid1809.120283

24. Wamae PM, Githeko AK, Otieno GO, Kabiru EW, Duombia SO. Early biting of the Anopheles gambiae s.s. and its challenges to vector control using insecticide treated nets in western Kenya highlands. Acta Trop (2015) 150:136-42. doi:10.1016/j.actatropica.2015.07.008

25. Ototo EN, Mbugi JP, Wanjala CL, Zhou G, Githeko AK, Yan G. Surveillance of malaria vector population density and biting behaviour in western Kenya. Malar J (2015) 14:244. doi:10.1186/s12936-015-0763-7

26. Kitau J, Oxborough RM, Tungu PK, Matowo J, Malima RC, Magesa SM, et al. Species shifts in the Anopheles gambiae complex: do LLINs successfully control Anopheles arabiensis? PLoS One (2012) 7:e31481. doi:10.1371/journal. pone.0031481 
27. Ndenga BA, Mulaya NL, Musaki SK, Shiroko JN, Dongus S, Fillinger U. Malaria vectors and their blood-meal sources in an area of high bed net ownership in the western Kenya highlands. Malar J (2016) 15:76. doi:10.1186/ s12936-016-1115-y

28. Wanjala CL, Zhou G, Mbugi J, Simbauni J, Afrane YA, Ototo E, et al. Insecticidal decay effects of long-lasting insecticide nets and indoor residual spraying on Anopheles gambiae and Anopheles arabiensis in Western Kenya. Parasit Vectors (2015) 8:588. doi:10.1186/s13071-015-1194-6

29. Ngonghala CN, Del Valle SY, Zhao R, Mohammed-Awel J. Quantifying the impact of decay in bed-net efficacy on malaria transmission. J Theor Biol (2014) 363:247-61. doi:10.1016/j.jtbi.2014.08.018

30. Zhou G, Li JS, Ototo EN, Atieli HE, Githeko AK, Yan G. Evaluation of universal coverage of insecticide-treated nets in western Kenya: field surveys. Malar $J$ (2014) 13:351. doi:10.1186/1475-2875-13-351

31. Bhatt S, Weiss DJ, Cameron E, Bisanzio D, Mappin B, Dalrymple U, et al. The effect of malaria control on Plasmodium falciparum in Africa between 2000 and 2015. Nature (2015) 526:207-11. doi:10.1038/nature15535

32. Lindblade KA, Eisele TP, Gimnig JE, Alaii JA, Odhiambo F, ter Kuile FO, et al. Sustainability of reductions in malaria transmission and infant mortality in western Kenya with use of insecticide-treated bednets: 4 to 6 years of follow-up. JAMA (2004) 291:2571-80. doi:10.1001/ jama.291.21.2571

33. Okiro EA, Hay SI, Gikandi PW, Sharif SK, Noor AM, Peshu N, et al. The decline in paediatric malaria admissions on the coast of Kenya. Malar J (2007) 6:151. doi:10.1186/1475-2875-6-151

34. O'Meara WP, Bejon P, Mwangi TW, Okiro EA, Peshu N, Snow RW, et al. Effect of a fall in malaria transmission on morbidity and mortality in Kilifi, Kenya. Lancet (2008) 372:1555-62. doi:10.1016/S0140-6736(08)61655-4

35. Okiro EA, Alegana VA, Noor AM, Mutheu JJ, Juma E, Snow RW. Malaria paediatric hospitalization between 1999 and 2008 across Kenya. Malaria paediatric hospitalization between 1999 and 2008 across Kenya. BMC Med (2009) 7:75. doi:10.1186/1741-7015-7-75

36. Rowe AK, Steketee RW. Predictions of the impact of malaria control efforts on all-cause child mortality in sub-Saharan Africa. Am J Trop Med Hyg (2007) 77:S48-55.

37. Binka F, Indome F, Smith T. Impact of spatial distribution of permethrin impregnated bed nets on child mortality in rural northern Ghana. Am J Trop Med Hyg (1998) 59:80-5.

38. Hawley WA, Phillips-Howard PA, Ter Kuile FO, Terlouw DJ, Vulule JM, Ombok M, et al. Community-wide effects of permethrin-treated bed nets on child mortality and malaria morbidity in western Kenya. Am J Trop Med Hyg (2003) 68:121-7.

39. Henry MC, Assi SB, Rogier C, Dossou-Yovo J, Chandre F, Guillet P, et al. Protective efficacy of lambda-cyhalothrin treated nets in Anopheles gambiae pyrethroid resistance areas of Cote d'Ivoire. Am J Trop Med Hyg (2005) 73:859-64.
40. Damien GB, Djenontin A, Rogier C, Corbel V, Bangana SB, Chandre F, et al. Malaria infection and disease in an area with pyrethroid-resistant vectors in southern Benin. Malar J (2010) 9:380. doi:10.1186/1475-2875-9-380

41. Tokponnon FT, Ogouyemi AH, Sissinto Y, Sovi A, Gnanguenon V, Cornelie S, et al. Impact of long-lasting, insecticidal nets on anaemia and prevalence of Plasmodium falciparum among children under five years in areas with highly resistant malaria vectors. Malar J (2014) 13:76. doi:10.1186/1475-2875-13-76

42. Ranson H, Lissenden N. Insecticide resistance in African Anopheles mosquitoes: a worsening situation that needs urgent action to maintain malaria control. Trends Parasitol (2016) 32:187-96. doi:10.1016/j.pt.2015.11.010

43. Mathanga DP, Mwandama DA, Bauleni A, Chisaka J, Shah MP, Landman KZ, et al. The effectiveness of long-lasting, insecticide-treated nets in a setting of pyrethroid resistance: a case-control study among febrile children 6 to 59 months of age in Machinga District, Malawi. Malar J (2015) 14:457. doi:10.1186/s12936-015-0961-3

44. Lindblade KA, Mwandama D, Mzilahowa T, Steinhardt L, Gimnig J, Shah M, et al. A cohort study of the effectiveness of insecticide-treated bed nets to prevent malaria in an area of moderate pyrethroid resistance, Malawi. Malar J (2015) 14:31. doi:10.1186/s12936-015-0554-1

45. Kawada H, Ohashi K, Dida GO, Sonye G, Njenga SM, Mwandawiro C, et al. Preventive effect of permethrin-impregnated long-lasting insecticidal nets on the blood feeding of three major pyrethroid-resistant malaria vectors in western Kenya. Parasit Vectors (2014) 7:383. doi:10.1186/1756-3305-7-383

46. Mulamba C, Riveron JM, Ibrahim SS, Irving H, Barnes KG, Mukwaya LG, et al. Widespread pyrethroid and DDT resistance in the major malaria vector Anopheles funestus in East Africa is driven by metabolic resistance mechanisms. PLoS One (2014) 9:e110058. doi:10.1371/journal.pone.0110058

47. Kawada H, Dida GO, Ohashi K, Komagata O, Kasai S, Tomita T, et al. Multimodal pyrethroid resistance in malaria vectors, Anopheles gambiae s.s., Anopheles arabiensis, and Anopheles funestus s.s. in Western Kenya. PLoS One (2011) 6:e22574. doi:10.1371/journal.pone.0022574

48. Kamau L, Agai D, Matoke D, Wachira L, Gikandi G, Vulule JM. Status of insecticide susceptibility in Anopheles gambiae sensu lato and Anopheles funestus mosquitoes from western Kenya. J Insect Sci (2008) 8:11. doi:10.1673/031.008.1101

Conflict of Interest Statement: The authors declare that the research was conducted in the absence of any commercial or financial relationships that could be construed as a potential conflict of interest.

Copyright (c) 2016 Zhou, Lee, Githeko, Atieli and Yan. This is an open-access article distributed under the terms of the Creative Commons Attribution License (CC BY). The use, distribution or reproduction in other forums is permitted, provided the original author(s) or licensor are credited and that the original publication in this journal is cited, in accordance with accepted academic practice. No use, distribution or reproduction is permitted which does not comply with these terms. 